\title{
Concentrado proteico de folhas de mandioca na alimentação de tilápias-do- nilo na fase de reversão sexual
}

\section{Leandro Bohnenberger ${ }^{1}$, Simone Damasceno Gomes ${ }^{2}$, Sílvia Renata Machado Coelho², Wilson Rogério Boscolo ${ }^{3}$}

\footnotetext{
${ }^{1}$ Mestrando em Engenharia Agrícola - UNIOESTE - Campus Cascavel/Paraná.

2 Engenharia Agrícola - UNIOESTE - Campus Cascavel/Paraná.

${ }^{3}$ Engenharia de Pesca - UNIOESTE - Campus Toledo/Paraná.
}

RESUMO - Este trabalho foi realizado com o objetivo de avaliar a inclusão de concentrado proteico de folhas de mandioca na alimentação de tilápias-do-nilo na fase de reversão sexual. Durante o período experimental, que durou 28 dias, foram utilizadas 300 larvas de tilápia com 7 dias de idade, distribuídas em 20 aquários com capacidade para 30 L, em um delineamento inteiramente casualisado, com cinco níveis do concentrado proteico de folhas de mandioca (0; 5; 10; 15 e $20 \%$ ), cada um com quatro repetições, considerando unidade experimental um aquário com 15 larvas. As cinco rações foram isoproteicas e isoenergéticas, com 38,6\% de proteína digestível e $3.300 \mathrm{kcal}$ de ED/kg de ração. Os valores médios de temperatura, $\mathrm{pH}$, oxigênio dissolvido e condutividade elétrica da água dos aquários durante o período experimental foram de $23,90 \pm 1,35^{\circ} \mathrm{C} ; 7,23 \pm 0,30 ; 5,15 \pm 0,84 \mathrm{mg} / \mathrm{L}$; e $105,91 \pm 4,73 \mu \mathrm{S} / \mathrm{cm}$, respectivamente. Ao final do período experimental, não foram observadas diferenças significativas no peso, no comprimento final, no ganho de peso nem na taxa de sobrevivência das larvas alimentadas com o concentrado proteico de folhas de mandioca. A utilização de concentrado proteico de folhas de mandioca em níveis de até $20 \%$ em rações para tilápia-do-nilo na fase de reversão sexual não prejudica o desempenho nem a sobrevivência dos animais.

Palavras-chave: avaliação de alimento, fonte de proteína, nutrição de peixes, Oreochromis niloticus, tilápia-do-nilo

\section{Cassava leaf protein concentrate in Nile tilapia diets during sex reversal phase}

\begin{abstract}
This paper aimed to evaluate the effect of inclusion of cassava leaf protein concentrate (CLPC) in Nile tilapia diets during sex reversal phase. During the experiment, which lasted for 28 days, 300 tilapia larvae at 7 days of age were distributed into 20 aquarium tanks with $30 \mathrm{~L}$ of water capacity in a complete randomized design, with 5 levels of cassava leaf protein concentrate $(0 ; 5 ; 10 ; 15$; and $20 \%)$, each one with four replicates. One aquarium with 15 larvae was considered the experimental unit. The five rations were iso-proteic and iso-energetic containing 38.6\% of digestible protein and 3,300 kcal of $\mathrm{DE} / \mathrm{kg}$ diet. The average values of temperature, $\mathrm{pH}$, dissolved oxygen and electric conductivity of the water in the experimental aquarium were $23.90 \pm 1.35^{\circ} \mathrm{C} ; 7.23 \pm 0.30 ; 5.15 \pm 0.84 \mathrm{mg} / \mathrm{L} ;$ and $105.91 \pm 4.73 \mu \mathrm{S} / \mathrm{cm}$, respectively. At the end of the experiment, no significant differences were observed on the weight, final length, weight gain and survival rate of the larvae that were fed cassava leaf protein concentrate. The use of cassava leaf protein concentrate at levels up to $20 \%$ in the diets for Nile tilapia in sex reversal phase do not harm the survival neither the performance of the animals.
\end{abstract}

Key Words: food evaluation, Nile tilapia, nutrition of fish, Oreochromis niloticus, protein source

\section{Introdução}

Um dos resíduos gerados na cultura da mandioca, especificamente no processo de colheita das raízes, éa folha. As proteínas das folhas de mandioca são alternativas de proteínas vegetais. Devido a sua fácil disponibilidade, podem ser utilizadas como suplemento alimentar, tanto para o homem como para animais. As folhas de mandioca são ricas em proteínas, vitaminas e minerais a baixo custo, todavia são normalmente desperdiçadas (Madruga \& Câmara, 2000).
Embora as folhas de mandioca sejam ricas em proteínas, vitaminas e minerais, seu consumo direto fica limitado por fatores como a presença de substâncias antinutritivas e/ou tóxicas e o elevado teor de fibras alimentares que não podem ser digeridas no estômago de animais monogástricos (Modesti, 2006).

A alternativa para melhorar o aproveitamento das folhas é a extração de proteínas, eliminando todos os produtos antinutricionais e tóxicos (Cereda \& Vilpoux, 2003). Ao avaliar cinco métodos de extração de proteínas de folhas 
de mandioca, Ferri et al. (2006) constataram que o método de extração por precipitação isoelétrica de Cereda \& Vilpoux (2003) e o método de extração por fermentação, citado por Chaves (1987), apresentaram maiores rendimentos de extração em comparação aos demais métodos, com a vantagem de que o método de extração por precipitação isoelétrica produz concentrados em menor tempo de extração.

Rações para peixes exigem altos níveis de proteína que são provenientes de alimentos de origem animal e vegetal. A proteína é o nutriente mais importante, pois é dos constituintes do organismo de animais em crescimento e, responsável pela formação de enzimas e hormônios (Pezzato, 1997). O concentrado proteico de folhas de mandioca tem alto valor nutritivo, baixo custo de produção e pode assim ser muito atrativo como fonte de proteína na alimentação animal (Fasuyi \& Aletor, 2005).

O objetivo neste estudo foi avaliar o efeito da utilização de concentrado proteico de folhas de mandioca na ração no desempenho e na taxa de sobrevivência de larvas de tilápiado-nilo (Oreochromis niloticus).

\section{Material e Métodos}

O experimento foi realizado no período de abril a maio de 2008 e teve 28 dias de duração. Foram utilizadas 300 larvas de tilápia-do-nilo (Oreochromis niloticus) com sete dias pós-eclosão, distribuídas em 20 aquários com capacidade para $30 \mathrm{~L}$, em delineamento inteiramente casualizado, e alimentadas com $0,5,10,15$ e $20 \%$ de concentrado proteico de folhas de mandioca na ração, em quatro repetições, considerando unidade experimental um aquário com 15 larvas.

Os aquários apresentavam sistema de aeração individual por meio de um soprador. Foi realizada renovação diária de aproximadamente $50 \%$ do volume total no início do experimento e $100 \%$ nos últimos 15 dias, por meio de duas sifonagens realizadas diariamente, uma no período da manhã, antes da primeira alimentação e outra no final da tarde, antes da última alimentação.

O concentrado proteico de folhas de mandioca foi obtido pelo método de extração por precipitação isoelétrica, citado por Cereda \& Vilpoux (2003) (Figura 1), utilizando-se folhas de mandioca com aproximadamente 12 meses de idade após o plantio. $\mathrm{Na}$ análise, apresentou a seguinte composição nutricional, em relação à matéria natural: matéria seca, 93,01\%; energia bruta, $5.527,00 \mathrm{kcal} / \mathrm{kg}$; proteína bruta, $48,42 \%$; extrato etéreo, $13,57 \%$; cinzas, $3,48 \%$.

Foram elaboradas cinco rações com $0 ; 5 ; 10 ; 15$ e 20\% de concentrado proteico de folhas de mandioca, todas isoproteicas, isocalóricas, isocálcicas e isofosfóricas e formuladas de acordo com a recomendação do NRC (1993) e de Hayashi et al. (2002) (Tabela 1). Na elaboração das rações, os alimentos foram processados individualmente em moinho tipo faca segundo Hayashi et al. (1999) e, em seguida, foram misturados. As rações foram fornecidas quatro vezes ao dia, às $8 \mathrm{~h} 30 \mathrm{~min}, 11 \mathrm{~h} 30 \mathrm{~min}, 14 \mathrm{~h} 30 \mathrm{~min} \mathrm{e}$ $17 \mathrm{~h} 30 \mathrm{~min}$, à vontade.

Tabela 1 - Composição das rações experimentais, calculada em relacão à matéria natural

\begin{tabular}{|c|c|c|c|c|c|}
\hline \multirow[t]{2}{*}{ Ingrediente } & \multicolumn{5}{|c|}{ Nível de concentrado proteico de folhas de mandioca $(\%)$} \\
\hline & 0 & 5 & 10 & 15 & 20 \\
\hline Farelo de soja & 40,468 & 37,142 & 33,817 & 30,491 & 27,165 \\
\hline Farinha de vísceras de aves & 40,000 & 40,000 & 40,000 & 40,000 & 40,000 \\
\hline Milho & 15,524 & 12,622 & 9,720 & 6,818 & 3,916 \\
\hline Concentrado proteico de folhas de mandioca & 0,000 & 5,000 & 10,000 & 15,000 & 20,000 \\
\hline Fosfato bicálcico & 0,994 & 1,075 & 1,157 & 1,238 & 1,319 \\
\hline Calcário calcítico & 0,152 & 0,114 & 0,076 & 0,038 & 0,000 \\
\hline Óleo de soja & 1,542 & 2,727 & 3,911 & 5,096 & 6,280 \\
\hline Suplemento mineral + vitamínico $^{1}$ & 1,000 & 1,000 & 1,000 & 1,000 & 1,000 \\
\hline Antioxidante (BHT) & 0,020 & 0,020 & 0,020 & 0,020 & 0,020 \\
\hline Sal & 0,300 & 0,300 & 0,300 & 0,300 & 0,300 \\
\hline \multicolumn{6}{|l|}{ Composição nutricional } \\
\hline Energia digestível $(\mathrm{kcal} / \mathrm{kg})^{2}$ & $3.300,00$ & $3.300,00$ & $3.300,00$ & $3.300,00$ & $3.300,00$ \\
\hline Proteína disgestível ${ }^{2}$ & 38,60 & 38,60 & 38,60 & 38,60 & 38,60 \\
\hline Proteína bruta & 44,34 & 44,95 & 45,56 & 46,17 & 46,78 \\
\hline Cálcio & 2,14 & 2,14 & 2,14 & 2,14 & 2,14 \\
\hline Fósforo total & 1,50 & 1,50 & 1,50 & 1,50 & 1,50 \\
\hline Extrato etéreo & 7,19 & 8,90 & 10,61 & 12,31 & 14,02 \\
\hline
\end{tabular}




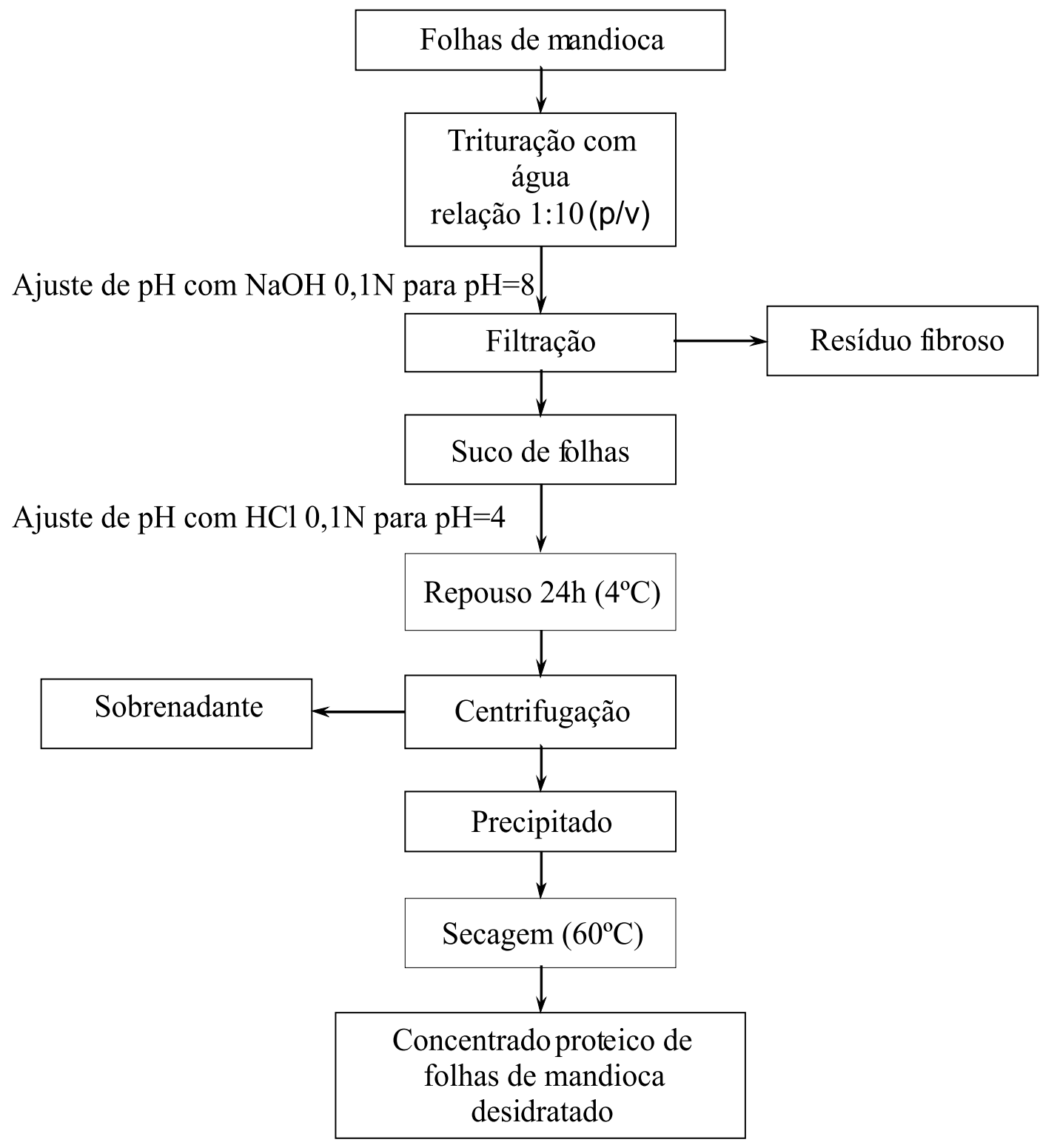

Figura 1 - Sequência de obtenção do concentrado proteico de folhas de mandioca - extração por precipitação isoelétrica (Cereda \& Vilpoux, 2003).

A temperatura $\left({ }^{\circ} \mathrm{C}\right)$ da água dos aquários foi aferida diariamente pela manhã $(8 \mathrm{~h})$ e à tarde $(17 \mathrm{~h})$, enquanto o $\mathrm{pH}$, o oxigênio dissolvido e a condutividade elétrica foram aferidos semanalmente, à tarde (17 h).

Ao final do período experimental, os peixes foram mantidos em jejum por 24 horas e, após este período, foram feitas as medidas individuais de peso $(\mathrm{g})$ e comprimento total $(\mathrm{cm})$ dos peixes de cada unidade experimental. Em seguida, os peixes foram secos em estufa de renovação e circulação de ar a $55^{\circ} \mathrm{C}$ por 72 horas e triturados, para posterior análise de umidade, cinzas, extrato etéreo e proteína bruta, conforme AOAC (1995).

Os dados obtidos foram submetidos à análise de variância e as médias comparadas pelo teste Tukey a 5\% de significância, pelo sistema de análises estatísticas, Sisvar, versão 4.3 


\section{Resultados e Discussão}

Os valores médios de temperatura, $\mathrm{pH}$, oxigênio dissolvido e condutividade elétrica durante o período experimental foram $23,90 \pm 1,35^{\circ} \mathrm{C} ; 7,23 \pm 0,30$; $5,15 \pm 0,84 \mathrm{mg} / \mathrm{Le} 105,91 \pm 4,73 \mu \mathrm{S} / \mathrm{cm}$, respectivamente. Os valores encontrados para os parâmetros físico-químicos da água encontram-se dentro da faixa recomendada para a aquicultura (Boyd, 1990).

Os valores médios de peso final, ganho de peso, comprimento final e sobrevivência não diferiram entre os níveis de concentrado proteico de folhas de mandioca a $5 \%$ de significância (Tabela 2).

$\mathrm{Na}$ literatura consultada, não foram encontrados trabalhos sobre os efeitos da inclusão de concentrado proteico de folhas de mandioca em rações sobre o desempenho e a sobrevivência de peixes. Entretanto, estudos com alimentos alternativos podem dar subsídios à produção de rações, mais baratas, de mesma qualidade nutricional e que proporcionem desempenho produtivo equivalente ao daquelas formuladas com alimentos convencionais (El-Sayed, 1999; Boscolo et al., 2002b; Meurer et al., 2003).

Ao final do período experimental os valores médios de peso final das tilápias alimentadas com rações contendo concentrado proteico de folhas de mandioca, não diferiram, a 5\% de significância, dos obtidos com a ração controle ( $0 \%$ de inclusão). Esses resultados estão de acordo com os encontrados por Souza \& Hayashi (2003), que empregaram farelo de algodão para alevinos de tilápia-donilo; Boscolo et al. (2005), que incluíram farinha de resíduos da indústria de filetagem de tilápias para tilápia-do-nilo na fase de reversão sexual; Galdioli et al. (2001), que utilizaram farelos de canola e algodão para alevinos de piavuçu (Leporinus macrocephalus); e Souza et al. (2004), que usaram farelo de canola e girassol para larvas de tilápia durante o período de reversão sexual.

Neste estudo, o ganho de peso não diferiu significativamente $(\mathrm{P}>0,05)$, daquela obtido com a inclusão de até $20 \%$ de concentrado proteico de folhas de mandioca em substituição ao farelo de soja. Os resultados deste trabalho assemelham-se ao obtido por Soares (2001), que concluiu que a substituição de até $35,40 \%$ do farelo de soja por farelo de canola na dieta não prejudica o ganho de peso de tilápia-do-nilo na fase de crescimento. El-Sayed (1990) observou que o farelo de algodão pode ser utilizado como única fonte proteica para Oreochromis mossambicus e tilápia-do-nilo, pois não afeta o desempenho desses peixes. Entretanto, resultados negativos em relação ao concentrado proteico de folhas de mandioca foram obtidos por Furuya et al. (2000), que trabalharam com 0, 7, 14, 21 e $28 \%$ de farinha de girassol e concluíram que esse alimento pode ser incluído em níveis de até $14 \%$ em dietas para tilápias-do-nilo na fase juvenil, pois níveis superiores promovem redução no desempenho dos animais.

$\mathrm{O}$ comprimento final, não apresentou diferença significativa ( $\mathrm{P}>0,05)$ entre os níveis de $0,5,10,15$ e $20 \%$ de concentrado proteico de folhas de mandioca na ração para tilápias. Essas características de desempenho produtivo não foram afetadas pelos níveis de concentrado proteico de folhas de mandioca, portanto esse alimento pode ser incluído na dieta da tilápia-do-nilo na fase de reversão sexual em níveis de até $20 \%$ sem ocasionar prejuízos no desempenho.

A uniformidade do lote em relação à sobrevivência não foi afetada de forma significativa $(\mathrm{P}>0,05), \log$ o os níveis de $0,5,10,15$ e $20 \%$ do concentrado proteico de folhas de mandioca na ração não afetaram a sobrevivência das larvas na fase de reversão sexual. Esse fato se deve, possivelmente, à formulação das rações isonutritivas, com base em nutrientes digestíveis e à ausência de fatores antinutricionais no concentrado proteico de folhas de mandioca. De acordo com Wobeto (2003), folhas de mandioca em plantas com 12 meses de idade apresentam níveis mais elevados de alguns nutrientes e mais baixos para a maioria dos antinutrientes, o que pode ter possibilitado a sobrevivência dos animais, em razão da melhor qualidade do concentrado. A grande vantagem do uso de concentrado proteico de folhas de mandioca como fonte alternativa de proteína vegetal são a abundância e

Tabela 2 - Desempenho e sobrevivência de tilápias-do-nilo alimentadas com rações contendo concentrado proteico de folhas de mandioca na fase de reversão sexual

\begin{tabular}{|c|c|c|c|c|c|c|}
\hline \multirow[t]{2}{*}{ Item } & \multicolumn{5}{|c|}{ Nível de concentrado proteico de folhas de mandioca $(\%)$} & \multirow[t]{2}{*}{ CV $(\%)$} \\
\hline & 0 & 5 & 10 & 15 & 20 & \\
\hline Peso final $(\mathrm{g})$ & $1,15 \mathrm{a}$ & $1,30 \mathrm{a}$ & $1,30 \mathrm{a}$ & $1,31 \mathrm{a}$ & $1,28 \mathrm{a}$ & 10,51 \\
\hline Comprimento final $(\mathrm{cm})$ & $4,06 \mathrm{a}$ & $4,20 \mathrm{a}$ & $4,22 \mathrm{a}$ & $4,22 \mathrm{a}$ & $4,21 \mathrm{a}$ & 3,14 \\
\hline Sobrevivência (\%) & $96,67 \mathrm{a}$ & $93,33 \mathrm{a}$ & $95,00 \mathrm{a}$ & $93,33 \mathrm{a}$ & $96,67 \mathrm{a}$ & 6,96 \\
\hline
\end{tabular}

Valores na mesma linha, seguidos da mesma letra, não diferem ( $\mathrm{P}>0,05)$ estatisticamente entre si a $5 \%$ de significância. 
a facilidade de transporte de folhas de mandioca, o que pode garantir fornecimento de matéria-prima durante todo o ano (Lê Guerroué, 2000).

Os teores médios de umidade, cinzas, extrato etéreo e proteína bruta das tilápias não diferiram estatisticamente entre os níveis de concentrado proteico de folhas de mandioca a 5\% de significância (Tabela 3).
As análises de composição química da tilápia-donilo são importantes, pois, quando se avaliam alimentos para peixes, as características de carcaça, como gordura e proteína, podem indicar possível desbalanço nutricional da ração testada ou ainda a presença de fatores antinutricionais nos alimentos avaliados (Boscolo et al., 2002a).

Tabela 3 - Composição química de tilápias-do-nilo alimentadas com rações contendo concentrado proteico de folhas de mandioca

\begin{tabular}{|c|c|c|c|c|c|c|}
\hline \multirow[t]{2}{*}{ Item $(\%)$} & \multicolumn{5}{|c|}{ Nível de concentrado proteico de folhas de mandioca $(\%)$} & \multirow[t]{2}{*}{$\mathrm{CV}(\%)$} \\
\hline & 0 & 5 & 10 & 15 & 20 & \\
\hline Umidade & $82,92 \mathrm{a}$ & $83,23 \mathrm{a}$ & $82,44 \mathrm{a}$ & $82,76 \mathrm{a}$ & $81,56 \mathrm{a}$ & 1,15 \\
\hline Extrato etéreo ${ }^{1}$ & $27,74 \mathrm{a}$ & $27,32 \mathrm{a}$ & $28,66 \mathrm{a}$ & $27,98 \mathrm{a}$ & $28,85 \mathrm{a}$ & 3,11 \\
\hline Proteína bruta ${ }^{1}$ & $50,41 \mathrm{a}$ & $50,26 a$ & $50,28 \mathrm{a}$ & $49,77 \mathrm{a}$ & $47,80 \mathrm{a}$ & 2,58 \\
\hline
\end{tabular}

Valores na mesma linha, seguidos da mesma letra, não diferem $(\mathrm{P}>0,05)$ estatisticamente entre si a 5\% de significância.

${ }^{1}$ Dados calculados com base na matéria seca.

\section{Conclusões}

O concentrado proteico de folhas de mandioca pode ser utilizado em níveis até $20 \%$ em rações para tilápias-do-nilo na fase de reversão sexual, pois a inclusão desse alimento na dieta não prejudica o desempenho nem a sobrevivência dos animais.

\section{Referências}

ASSOCIATION OF OFFICIAL ANALYTICAL CHEMISTS - AOAC. Official methods of analysis of the Association of the Analytical Chemists. 16.ed. Washintgton, 1995. 1141p.

BOSCOLO, W.R.; HAYASHI, C.; MEURER, F. Digestibilidade aparente da energia e nutrientes de alimentos convencionais e alternativos para a tilápia-do-nilo (Oreochromis niloticus, L.). Revista Brasileira de Zootecnia, v.13, n.2, p.539-545, 2002a.

BOSCOLO, W.R.; HAYASHI, C.; MEURER, F. Farinha de varredura de mandioca (Manihot esculenta) na alimentação de alevinos de tilápia-do-nilo (Oreochromis niloticus L.). Revista Brasileira de Zootecnia, v.13, n.2, p.545-551, 2002b.

BOSCOLO, W.R.; HAYASHI, C.; MEURER, F. et al. Farinha de resíduos da filetagem de tilápias na alimentação de tilápia-donilo (Oreochromis niloticus) na fase de reversão sexual. Revista Brasileira de Zootecnia, v.34, n.6, p.1807-1812, 2005.

BOYD, C. Water quality in ponds for aquaculture. London: Birmingham Publishing Co., 1990. 482p.

CEREDA, M.P.; VILPOUX, O. Potencialidades das proteínas de folhas de mandioca. In: CEREDA, M.P. (Ed.) Tecnologias, usos e potencialidades de tuberosas amiláceas latino americanas. São Paulo: Fundação Cargill, 2003. v.3, p.683-693.

CHAVES, J.G. Extrato protéico das folhas de mandioca. Revista Informe Agropecuário, v.13, n.145, p.47-52, 1987.

EL-SAYED, A.F.M. Alternative dietary protein sources for farmed tilápia Oreochromis spp. Aquaculture, v.179, p.149-168, 1999.

EL-SAYED, A.-F.M. Long-term evaluation of cotton seed meal as a protein source for Nile tilapia Oreochromis niloticus. Aquaculture, v.84, p.315-320, 1990.
FASUYI, O.A.; ALETOR, V.A. Varietal Composition and funtional properties of cassava (Manihot esculenta, Crantz) leaf meal and leaf protein concentrates. Paskistan Journal of Nutrition, v.1, n.1, p.43-49, 2005.

FERRI, P.; EVARINI, J.A.; DAMASCENO, S. et al. Avaliação de métodos de extração de proteínas para obtenção de concentrados protéicos de folhas de mandioca. In: CONGRESSO BRASILEIRO DE ENGENHARIA AGRíCOLA, 35., 2006. João Pessoa. Anais... João Pessoa: Congresso Brasileiro de Engenharia Agrícola, [2006]. (CD-ROM).

FURUYA, V.R.B.; FURUYA, W.M.; HAYASHI, C. et al. Niveles de inclusión de harina de girasol en la alimentación de la tilapia del Nilo (Oreochromis niloticus), en etapa juvenil. Revista Zootecnia Tropical, v.18, n.1, p.91-106, 2000.

GALDIOLI, E.M.; HAYASHI, C.; FARIA, A.C.E.A. et al. Substituição parcial e total da proteína do farelo de soja pela proteína dos farelos de canola e algodão em dietas para alevinos de piavuçu (Leporinus macrocephalus). Acta Scientiarum, v.23, n.4, p. 841-847, 2001.

HAYASHI, C.; BOSCOLO, W.R.; SOARES, C.M. et al. Exigência de proteína digestível para larvas de tilápia-do-nilo (Oreochromis niloticus) durante a reversão sexual. Revista Brasileira de Zootecnia, v.31, n.2, p.823-828, 2002.

HAYASHI, C.; BOSCOLO, W.R.; SOARES, C.M. et al. Uso de diferentes graus de moagem dos ingredientes em dietas para a tilápia-do-nilo (Oreochromis niloticus L.) na fase de crescimento. Acta Scientiarum, v.21, n.3, p.733-737, 1999.

LE GUERROUÉ J.L. Extração e valorização das proteínas da folha de mandioca. Brasília: Laboratório de Ciências de Alimentos, Universidade Católica de Brasília, 2000. 13p. (Projeto de Pesquisa).

MADRUGA, M.S.; CÂMARA, F.S. The chemical composition of multimistura as a food supplement. Food Chemistry, v.68, n.1, p.41-44, 2000.

MEURER, F.; HAYASHI, C.; BOSCOLO, W.R. Digestibilidade aparente dos nutrientes e energia de alguns alimentos proteicos para juvenis de tilápia-do-nilo (Oreochromis niloticus). Revista Brasileira de Zootecnia, v.32, n.6, p.1801-1809, 2003.

MODESTI, C.F. Obtenção e caracterização de concentrado protéico de folhas de mandioca submetido a diferentes tratamentos. 73f. 2006. Dissertação (Mestrado em Agroquímica e Agrobioquímica) - Universidade Federal de Lavras, Lavras. 
NATIONAL RESEARCH COUNCIL - NRC. Nutrient requirements of warmwater, fishes and shellfishes: nutrient requirements of domestics animals. Washington, D.C: 1993. 114p.

PEZZATO, L.E. O Estabelecimento das exigências nutricionais das espécies de peixes cultivadas. In: SIMPÓSIO SOBRE MANEJO E NUTRIÇÃO DE PEIXES, 1997, Piracicaba. Anais... Piracicaba: p.45-62, 1997.

SOARES, C.M.; HAYASHI, C.; FARIA, A.C.E.A. et al. Substituição da proteína do farelo de soja pela proteína do farelo de canola em dietas para a tilápia-do-nilo (Oreochromis niloticus) na fase de crescimento. Revista Brasileira de Zootecnia, v.30, n.4, p. $1172-1177,2001$
SOUZA, S.R.; HAYASHI, C.; GALDIOLI, E.M. et al. Diferentes fontes protéicas de origem vegetal para tilápia-do-nilo (Oreochromis niloticus L.) durante a reversão sexual. Acta Scientiarum, v.26, n.1, p.21-28, 2004

SOUZA, S.R.; HAYASHI, C. Avaliação do farelo de algodão na alimentação de alevinos de tilápia-do-nilo (Oreochromis niloticus L.). Revista Zootecnia Tropical, v.21, n.4, p.383-398, 2003. WOBETO, C. Nutrientes e antinutrientes da farinha de folhas de mandioca (Manihot esculenta Crantz) em três idades da planta. 82f. 2003. Dissertação (Mestrado em Agroquímica e Agrobioquímica) - Universidade Federal de Lavras, Lavras. 